\title{
Iron stores in blood donors: A literature mini review
}

\author{
Akram Aghamohammadi ${ }^{1}$, Mahtab Maghsoodlu ${ }^{1}$, Hosein Teimori Naghadeh ${ }^{1}$, Shirin \\ Ferdowsi ${ }^{1 *}$
}

1. Blood Transfusion Research Center, High Institute for Research and Education in Transfusion Medicine, Tehran, Iran

*Corresponding author:Tel: +98 2144720740 Fax: +98 2144720740

Address: Blood Transfusion Research Center, High Institute for Research and Education in Transfusion

Medicine, Tehran, Iran

E-mail: ferdowsishirin@gmail.com

Received; 2017/07/18 revised; 2017/07/29 accepted; 2017/09/17

\begin{abstract}
An increase in the frequency of blood donation among the donor population is liable to result in excessive iron loss and development of iron deficiency anemia. In the majority of blood banks, hemoglobin and/or hematocrit measurements are used as screening tests for the ability to donate blood even though iron stores may be depleted in donors with hemoglobin values above the arbitrarily defined limit for anemia. In the present study, we have reviewed the iron deficiency in blood donors and characteristics which predispose to this condition.
\end{abstract}

Keywords: Blood donors, Iron stores

\section{Introduction}

The occurrence of iron depletion and deficiency in first-time and repeat blood donors is well-documented in the transfusion medicine literature (1-3). With each whole blood (WB) donation, male donors lose $242 \pm 17 \mathrm{mg}$ and female donors lose $217 \pm 11 \mathrm{mg}$ of iron (1). Given that normal iron stores in men and women are $1000 \mathrm{mg}$ and $350 \mathrm{mg}$, respectively, maintenance of iron balance is a challenge in the blood donors. Iron deficiency is a significant cause of deferral. If iron is not replaced, donors may become iron deficient. All blood donors are screened at each visit for hemoglobin $(\mathrm{Hb})$ levels. Even among blood donors who have normal $\mathrm{Hb}$ values, iron deficiency is prevalent (4). Therefore, $\mathrm{Hb}$ levels alone are inadequate for distinguishing blood donors with iron deficiency without anemia (5). Moreover, some deferred blood donors do not return to donate, especially first-time donors. While there is a steady push for recruitment of more regular donors and encouragement of first time donors to give blood regularly in order to increase the safety of national blood supplies(6). Blood banks have the responsibility to prevent anemia among donors. In the present study, we have reviewed the iron deficiency in blood donors and characteristics which predispose to this condition.

Diagnostic tests of iron deficiency in blood donors: In the majority of blood banks, $\mathrm{Hb}$ has generally been used as a screening test for the suitability to give blood. However, it has been reported that this parameter has poor sensitivity, especially in the detection of early stages of iron deficiency. Indeed, an accurate diagnosis of iron deficiency requires several laboratory tests. Measurements of serum iron, serum ferritin concentrations, mean cell volume (MCV) and mean corpuscular hemoglobin $(\mathrm{MCH})$ can be used with a high degree of accuracy and precision $(7,8)$. In the study by Simon et al, using ferritin $\leq 12 \mathrm{ng} / \mathrm{ml}$ to define iron depletion the overall frequency in regular blood donors was $8 \%$ in males and $23 \%$ in females(9). A systematic review found 
ferritin levels to be superior to several other tests (MCV, \%Sat, zinc protoporphyrin), and ferritin $<15 \mathrm{ng} / \mathrm{mL}$ confirms the diagnosis of iron deficiency (10). Other studies suggest higher levels (22-40 $\mu \mathrm{g} / \mathrm{L})$ more sensitively reflect irondeficient erythropoiesis (10-12). As in clinical studies, it is obvious that a ferritin cutoff of $12 \mathrm{ng} / \mathrm{mL}$ is a specific marker of iron depletion in blood donors, but also lacks sensitivity (13). One study found that this cutoff failed to identify iron depletion in over $1 / 3$ of cases in blood donors (14). The investigators found a higher ferritin level, $22 \mathrm{ng} / \mathrm{mL}$, more indicative of functional iron depletion. These investigations were not based on the "gold standard" bone marrow iron stains or a hematologic response to iron, but relied (9). In order to find out the usefulness of serum iron and ferritin for correct diagnosis of iron deficiency in hospitalized patients, Burns et al (15) compared the results of serum iron and ferritin tests with the presence of stainable iron in bone marrow aspirates from 301 patients. Iron deficiency was correctly detected by serum iron in only $41 \%$ and ferritin in $90 \%$ of patients, respectively. These investigators concluded that iron measurements, not have the adequate sensitivity and/or specificity for precise diagnosis of iron deficiency.

Iron stores in regular and first-time blood donors: In Adediran et al (16) study, the mean serum ferritin level was significantly lower in the regular donors than in the first time donors. SzymczykNuzka et al (17) when determining the prevalence of iron deficiency in regular blood donors noted a lower serum ferritin in this group in contrast with first-time donors who had normal serum ferritin levels. Norashikin et al (18) also reported significantly lower serum ferritin levels in regular blood donor. Several investigators have noted a significant reduction in ferritin levels with increasing donations (18-21). However, Vilzu et al (22) reported no significant difference between ferritin levels in controls and donors donating less than 20 units. Akpotuzor et al (23) reported that there was no observable difference in biochemical iron parameters between regular donors and normal controls. In contrast, several other studies have documented lower serum iron levels in regular blood donors compared with healthy controls (19).

The effect of repeated blood donations on the iron status of male and female blood donors

The results of a study on the iron status of male Saudi blood donors showed that increased number of donations result in iron deficiency anemia, although the level of hemoglobin remained acceptable for blood donation(24). Results of a study in Iran (25) showed that $11 \%$ of male regular donors and $0.8 \%$ of first-time donors had iron store depletion. Among blood donors, premenopausal women are at high risk of iron deficiency, (26) and preventing and alleviating this problem is a major concern for blood services (27). Postmenopausal women can donate blood without becoming iron deficient if they have initially had adequate iron stores (28). However, women of childbearing age are at increased risk of iron deficiency if they donate blood more than one unit a year (29). Cable et al (30) study showed that absent iron stores (AIS), and iron deficient erythropoiesis (IDE), are highly prevalent in frequent blood donors. They defined AIS as a ferritin level below $12 \mathrm{ng} / \mathrm{mL}$ and IDE as present if the $\log$ of the ratio of soluble transferrin receptor to ferritin was greater than or equal to 2.07. In regular male donors, $16.4 \%$ had AIS and $48.7 \%$ IDE, while $27.1 \%$ and $66.1 \%$ of female regular donors have AIS and IDE, respectively. In a study by Yousefinejad et al (31) the donors with more than five instances of donation have considerably lower serum ferritin than ones with five instances of donation and less, comparing with the results of two previous studies performed in Iran $(32,33)$, while a study in Pakistan mentioned the relationship 
between four and more instances of donation in the past two years and iron deficiency (34). Therefore, it seems primary evaluations before blood donation is necessary for regular male donors from the fifth donation onwards with not just attention to $\mathrm{Hb}$ level; usage of iron supplements in this group should be evaluated and this matter had been emphasized in previous studies as well(32, 34). A study by Mirrezaie et al, (35) indicated that replacing the iron lost at donation can protect the female regular donors from iron deficiency, and assist in retaining this group of donors for future donation.

\section{Predictors of iron levels in blood} donors: Rigas et al. (36) published a paper in which they described predictors of iron levels in 14,737 Danish blood donors. Among high-frequency donors (more than nine donations in the past 3 years), they found iron deficiency (ferritin below 15 $\mathrm{ng} / \mathrm{ml}$ ) in 9,39 , and $22 \%$ of men, premenopausal women, and postmenopausal women, respectively. The strongest predictors of iron deficiency were gender, the number of blood donations in a 3-year period, menopausal status, and the time since previous donation. Other major factors included age, weight, and intensity of menstruation, iron tablets and vitamin pills. Cable et al, (30) found that donation frequency is the strongest predictor for iron stores. Furthermore, they report that gender, weight, iron supplements, dairy products, and age for women are significantly associated with AIS. They also reported that age in men, smoking, menstruation status, giving birth, and beef are associated with IDE. Furthermore, smoking and time since last donation are correlated with a lower risk of AIS (3). Both pica and restless legs syndrome (RLS) have been reported to occur in blood donors (37-39). Serum ferritin levels below $45-50 \mathrm{mcg} / \mathrm{L}$ have been found to exacerbate restless legs syndrome (RLS) $(40,41)$. In a study by Bryant et al,(42) the presence of pica and restless legs syndrome (RLS) was prospectively assessed in blood donors. Pica was reported in $11 \%$ of donors with iron depletion/deficiency, compared with $4 \%$ of iron-replete donors. Female sex, younger age, and lower MCV and transferrin saturation values were significantly associated with pica. RLS was reported in $16 \%$ of subjects with iron depletion/deficiency compared with $11 \%$ of iron-replete donors. Iron replacement generally resulted in improvement of RLS symptoms, however, at least 4-6 weeks of iron therapy was necessary. Bryant et al, (42) found an important association of pica with finger sticks $\mathrm{Hb}$ of less $11.5 \mathrm{~g} / \mathrm{dL}$ in female and less than $12.5 \mathrm{~g} / \mathrm{dL}$ in male donors.

\section{Conclusion}

Early detection of iron deficiency among donors would allow suitable readjustment of donation intervals and would guide the use of iron supplementation. Screening donors' serum ferritin levels at the time of first donation and then once every year is a very rational way to pick up an iron deficiency in a voluntary blood donor population. On the other hand, regular blood donation has several benefits, one of which is preventing enhance of body iron which can cause free radical formation in the body. Iron may also have deleterious effects on vascular function by increasing reactive oxygen species locally, decreasing the bioavailability of nitric oxide, impairing vasorelaxation, and promoting platelet adhesion and aggregation (43). In vitro studies have shown that iron acutely promotes platelet reactivity (44) and an increased risk of myocardial infarction (45).

\section{Acknowledgements}

The authors acknowledge blood transfusion research center, High institute for research and Education in Transfusion Medicine, Tehran, Iran. 


\section{References}

1. Simon TL. Iron, iron everywhere but not enough to donate. Transfusion. 2002; 42(6):664.

2. Bryant BJ, Yau YY, Arceo SM, Daniel-Johnson J, Hopkins JA, Leitman SF. Iron replacement therapy in the routine management of blood donors. Transfusion. 2012; 52(7):156675.

3. Cable RG, Glynn SA, Kiss JE, Mast AE, Steele WR, Murphy EL, et al. Iron deficiency in blood donors: the REDS-II Donor Iron Status Evaluation (RISE) study. Transfusion. 2012; 52(4):702-11.

4. Baart AM, Noord PA, Vergouwe Y, Moons KG, Swinkels DW, Wiegerinck ET, et al. High prevalence of subclinical iron deficiency in whole blood donors not deferred for low hemoglobin. Transfusion. 2013; 53(8):1670-7.

5. Oliveira F, Rocha S, Fernandes R. Iron metabolism: from health to disease. J Clin Lab Anal. 2014;28(3):210-8

6. Nadarajan VS, Eow GI. Anaemia and iron status among blood donors in a blood transfusion unit in Malaysia. Malays J Pathol. 2002; 24(2):99-102.

7. Røsvik A, Ulvik R, Wentzel-Larsen T, Hervig $\mathrm{T}$. The effect of blood donation frequency on iron status. Transfusion and Apheresis Science. 2009; 41(3):165-9.

8. Nadarajan V, Sthaneshwar P, Eow G. Use of red blood cell indices for the identification of iron deficiency among blood donors. Transfusion Medicine. 2008;18(3):184-9.

9. Simon TL, Garry PJ, Hooper EM. Iron stores in blood donors. Jama. 1981; 245(20):2038-43.

10. Guyatt GH, Oxman AD, Ali M, Willan A, McIlroy W, Patterson C. Laboratory diagnosis of iron-deficiency anemia. J Gen Intern Med. 1992; 7(2):145-53.
11. Suominen P, Punnonen K, Rajamäki A, Irjala K. Serum transferrin receptor and transferrin receptor-ferritin index identify healthy subjects with subclinical iron deficits. Blood. 1998; 92(8):2934-9.

12. Mast AE, Blinder MA, Gronowski AM, Chumley C, Scott MG. Clinical utility of the soluble transferrin receptor and comparison with serum ferritin in several populations. Clin Chem. 1998; 44(1):45-51.

13. Punnonen K, Rajamaki A. Evaluation of iron status of Finnish blood donors using serum transferrin receptor. Transfus Med. 1999; 9(2):131-4.

14. Thorpe SJ, Heath A, Sharp G, Cook J, Ellis R, Worwood M. A WHO Reference Reagent for the Serum Transferrin Receptor (sTfR): international collaborative study to evaluate a recombinant soluble transferrin receptor preparation. Clin Chem Lab Med. 2010; 48(6):815-20.

15. Burns E, Goldberg S, Lawrence C, Wenz B. Clinical utility of serum tests for iron deficiency in hospitalized patients. Am J Clin Pathol. 1990; 93(2):240-5.

16. Adediran A, Uche EI, Adeyemo TA, Damulak DO, Akinbami AA, Akanmu AS. Iron stores in regular blood donors in Lagos, Nigeria. J Blood Med. 2013; 4:75-80.

17. Szymczyk-Nuzka M, Wołowiec D. Iron stores in regular blood donors. Pol Arch Med Wewn. 2003; 110(6):141521.

18. Norashikin J, Roshan T, Rosline H, Zaidah AW. A study of serum ferritin levels among male blood donors in Hospital Universiti sains Malaysia. Southeast Asian J Trop Med Public Health. 2006;37(2):370-3

19. Jeremiah ZA, Koate BB. Anaemia, iron deficiency and iron deficiency anaemia among blood donors in Port 
Harcourt, Nigeria. Blood Transfus. 2010; 8(2):113-7.

20. Hoque $\mathrm{MM}^{1}$, Adnan SD, Karim S, AlMamun MA, Faruki MA, Islam K, et al. Relationship between Serum Iron Profile and Blood Groups among the Voluntary Blood Donors of Bangladesh. Mymensingh Med J. 2016; 25(2):340-8.

21. Milman N. Serum ferritin in Danes: studies of iron status from infancy to old age, during blood donation and pregnancy. Int J Hematol. 1996; 63(2):103-36.

22. Mahida VI, Bhatti A, Gupte SC. Iron status of regular voluntary blood donors. Asian J Transfus Sci. 2008; 2(1):9-12.

23. Akpotuzor J, Isong C, Okpokam O, Etukudo M. Levels of serum iron, total iron binding capacity, transferrin saturation fraction and packed cell volume of blood donors in Calabar, Cross River State, Nigeria. Pakistan J Nutrition. 2008; 7(3):500-2.

24. Abdullah SM. The effect of repeated blood donations on the iron status of male Saudi blood donors. Blood Transfus. 2011; 9(2):167-71.

25. Deyhim MR, Ahmadinejad M. Iron Stores in Male Blood Donors in Tehran Regional Blood Transfusion Center. IJBC. 2011;3: 107-111

26. Badami KG, Taylor K. Iron status and risk-profiling for deficiency in New Zealand blood donors. N Z Med J. 23;121(1274):50-60

27. Boulton F. Evidence-based criteria for the care and selection of blood donors, with some comments on the relationship to blood supply, and emphasis on the management of donation-induced iron depletion. Transfus Med. 2008; 18(1):13-27.

28. Garry PJ, Wayne SJ, Koehler KM, Pathak DR, Baumgartner RN, Simon TL. Prediction of iron absorption based on iron status of female blood donors. Am J Clin Nutr. 1992; 56(4):691-8.
29. Hunt W, Garry P. Iron supplementation for menstruating female blood donors. Transfusion. 1984; 24(6):469-72.

30. Cable RG, Glynn SA, Kiss JE, Mast AE, Steele WR, Murphy EL, et al. Iron deficiency in blood donors: analysis of enrollment data from the REDS-II Donor Iron Status Evaluation (RISE) study. Transfusion. 2011; 51(3):51122.

31. Yousefinejad V, Darvishi N, Arabzadeh M, Soori M, Magsudlu M, Shafiayan M. The evaluation of iron deficiency and anemia in male blood donors with other related factors. Asian J Transfus Sci. 2010; 4(2):123.

32. Javadzadeh Shahshahani H, Attar M, Taher Yavari M. A study of the prevalence of iron deficiency and its related factors in blood donors of Yazd, Iran, 2003. Transfusion Medicine. 2005; 15(4):287-93.

33. Djalali M, Neyestani TR, Bateni J, Siassi F. The effect of repeated blood donations on the iron status of Iranian blood donors attending the Iranian blood transfusion organization. Int $\mathbf{J}$ Vitam Nutr Res. 2006; 76(3):132-7.

34. Badar A, Ahmed A, Ayub M, Ansari AK. Effect of frequent blood donations on iron stores of non anaemic male blood donors. J Ayub Med Coll Abbottabad. 2002; 14(2):24-7.

35. Mirrezaie S, Parsi R, Torabgahromi S, Askarian M. Low dose, short-term iron supplementation in female blood donors of childbearing age: A randomized, double-masked, placebocontrolled study. IJMS. 2015; 33(3):138-43.

36. Rigas AS, Sørensen CJ, Pedersen OB, Petersen MS, Thørner LW, Kotzé S, et al. Predictors of iron levels in 14,737 Danish blood donors: results from the Danish Blood Donor Study. Transfusion. 2014; 54(3pt2):789-96.

37. Silber MH, Richardson JW, editors. Multiple blood donations associated with iron deficiency in patients with 
restless legs syndrome. Mayo Clinic Proceedings. 2003; 78(1):52-4.

38. Ulfberg J, Nyström B. Restless legs syndrome in blood donors. Sleep medicine. 2004; 5(2):115-8.

39. Allen RP. Iron, RLS and blood donations. Sleep medicine. 2004; 5(2):113-4.

40. Aul EA, Davis BJ, Rodnitzky RL. The importance of formal serum iron studies in the assessment of restless legs syndrome. Neurology. 1998; 51(3):912.

41. Sun ER, Chen CA, Ho G, Earley CJ, Allen RP. Iron and the restless legs syndrome. Sleep. 1998; 21(4):371-7.

42. Bryant BJ, Yau YY, Arceo SM, Hopkins JA, Leitman SF. Ascertainment of iron deficiency and depletion in blood donors through screening questions for pica and restless legs syndrome. Transfusion. 2013; 53(8):1637-44.

43. Russo G, Leopold JA, Loscalzo J. Vasoactive substances: nitric oxide and endothelial dysfunction in atherosclerosis. Vascul Pharmacol. 2002; 38(5):259-69.

44. Pratico D, Pasin M, Barry OP, Ghiselli A, Sabatino G, Iuliano L, et al. IronDependent Human Platelet Activation and Hydroxyl Radical Formation Involvement of Protein Kinase C. Circulation. 1999; 99(24):3118-24.

45. Salonen JT, Nyyssönen K, Korpela H, Tuomilehto J, Seppänen R, Salonen R. High stored iron levels are associated with excess risk of myocardial infarction in eastern Finnish men. Circulation. 1992; 86(3):803-11. 